\title{
Fixação de fraturas ilíacas em cães com parafusos, fios de aço e cimento ósseo de polimetilmetacrilato
}

\author{
Canine iliac fracture fixation with screws, orthopedic wire and polymethylmethacrylate \\ bone cement
}

\author{
Claudio Roehsig ${ }^{\text {I* }}$ Leandro Branco Rocha ${ }^{\mathrm{I}}$ Durval Barauna Junior ${ }^{\mathrm{I}}$ Ricardo Chioratto $^{\mathrm{I}}$ \\ Sérgio Ricardo Araújo de Melo e Silva' ${ }^{\mathrm{I}}$ Bernardo KemperII Felipe Purcell de Araújo ${ }^{\mathrm{II}}$ \\ Ana Carolina Medeiros de Almeida ${ }^{\text {II }}$ Eduardo Alberto Tuduri ${ }^{\mathrm{I}}$
}

\section{RESUMO}

O presente trabalho teve como objetivo verificar a recuperação da locomoção e o tempo para cicatrização óssea de fraturas ilíacas fixadas com parafusos, fios de aço e cimento ósseo de polimetilmetacrilato. Dezesseis cães de ambos os sexos, com peso de 1,8 a $16 \mathrm{~kg}$ e idade entre sete meses e 11 anos, foram submetidos à osteossíntese da fratura de ílio, provocadas por acidente automobilístico. Em dois animais, realizou-se osteossíntese bilateral, totalizando 18 ossos ilíacos operados. A abordagem ao ílio foi lateral e quando necessária estendida caudalmente através da osteotomia do trocanter maior. As fraturas foram reduzidas e, em cada segmento ósseo, foram implantados dois a três parafusos e banda de tensão com fio de aço entre os parafusos adjacentes à linha de fratura. Sobre esses implantes aplicou-se cimento ósseo misturado com cefazolina sódica e após o endurecimento prosseguiu-se com a síntese dos tecidos moles com suturas rotineiramente utilizadas na clinica cirúrgica. No período pós-operatório, foram realizadas avaliações até 90 dias após a osteossíntese e observou-se locomoção apropriada em 15 animais. Avaliações radiográficas demonstraram sinais de completa consolidação óssea entre 60 e 90 dias. Falha da estabilização ocorreu em dois casos, obrigando a reintervenção cirúrgica em um deles. A partir dos resultados obtidos, é possível concluir que, em cães com até $16 \mathrm{~kg}$ de peso, a fixação de fraturas ilíacas utilizando parafusos cimentados com PMMA constitui uma eficiente técnica, que proporciona adequada estabilidade, precoce recuperação funcional e cicatrização óssea.

Palavras-chave: fraturas ilíacas, polimetilmetacrilato, cimento ósseo, cães.

\section{ABSTRACT}

The present study aimed to verify the time for locomotion recovery and bone healing in canine iliac fractures fixated with screws, orthopedic wires and methylmetacrylate bone cement. Sixteen dogs from both genders accidentally hit by a car and showing iliac fractures were included. Dogs aged from 7 months to 11 years and weighted between 1.8 and $16.0 \mathrm{~kg}$. Two dogs had bilaterally fractures stabilized, totalizing 18 ilium osteosynthesis performed. The ilium was achieved via lateral approach. The fractures were reduced and on each bone segment was inserted two to three screws connected by a band tension. Over them a mixture of bone cement added with cefalozin was applied as a definitive fixation device. Suture of soft tissues was made as usual. Postoperative evaluations were periodically performed. After 3 months, 15 dogs showed proper use of the operated limb. Radiographic signs of complete bone healing were observed between 60 and 90 days. Stabilization failure occurred in two cases and one of them required another surgery. Both cases showed a good outcome. Based on these results it was possible to conclude that in dogs weighting up to $16.0 \mathrm{~kg}$, iliac fracture fixation with screws, orthopedic wires and bone cement is an efficient technique promoting early limb use and complete bone healing as a result of adequate bone stabilization.

Key words: ilium fractures, polymethylmethacrylate, bone cement, dogs.

\section{INTRODUÇÃO}

Fraturas da pelve representam 20 a $30 \%$ das fraturas observadas em cães e gatos (OLMESTEAD, 1995), sendo a maioria causada por acidentes automobilísticos (BETTS, 1998; WENDELBURG, 1998). Fraturas do ílio ocorrem em aproximadamente $46 \%$ das pelves traumatizadas e apresentam-se geralmente oblíquas ou transversas no corpo desse osso, mas

\footnotetext{
IPrograma de Pós-graduação em Ciência Veterinária (PPGCV), Departamento de Medicina Veterinária (DMV), Universidade Federal Rural de Pernambuco (UFRPE). Rua Dom Manoel de Medeiros s/n, 52171-900, Recife, PE,Brasil. E-mail: roehsig@yahoo.com.br.*Autor para correspondência.

IIDMV, UFRPE, Recife, PE, Brasil.
} 
também podem ocorrer fraturas múltiplas e cominutiva. Fraturas no ísquio e no púbis geralmente ocorrem juntamente com as de ílio (PIERMATTEI \& FLO, 1999).

Durante a locomoção, o ílio é uma importante interface de cargas entre os membros pélvicos e a coluna vertebral. Quando fraturado, fica comprometida essa interação mecânica, prejudicando a função motora do membro pélvico. A estabilização cirúrgica devolve as condições estruturais adequadas para locomoção (OLMSTEAD, 1995).

Com freqüência, o ílio fraturado apresenta o segmento caudal deslocado cranial e medialmente, reduzindo a amplitude do canal pélvico e, por vezes, comprometendo o nervo ciático que se localiza medialmente (OLMSTEAD, 1995). A osteossíntese é recomendada especialmente em cães com sobrepeso ou ainda os que adquiriram múltiplas lesões músculoesqueléticas durante o trauma (JACOBSON \& SCHRADER, 1987). BROWN et al (1975) afirmaram que a rígida estabilização proporciona precoce deambulação e cicatrização adequada do osso.

Na literatura especializada, constam relatos da fixação interna de fraturas e luxações com polimetilmetacrilato (PMMA) associado a pinos e parafusos. Pode-se citar ROUSE \& MILLER (1975) e WONG \& EMMS (1992), que utilizaram esse material na fixação da coluna vertebral; SUMMER-SMITTH \& WATERS (1976), que o utilizaram em ossos longos; LEWIS et al. (1997), em fraturas acetabulares e LIDBETTER \& WONG (2000), utilizaram em fraturas do colo da escápula, entre outros.

ALVAREZ \& MARTINEZ (1998) utilizaram pinos de Steinmann ou parafusos cimentados com PMMA, para fixação do ílio após osteotomia tripla da pelve em 14 cães de grande porte, sendo bilateral em seis animais. Após uma semana, os animais utilizavam o membro na locomoção. Na avaliação radiográfica, o tempo necessário para cicatrização óssea foi similar ao dos demais métodos de fixação citados na literatura.

Este trabalho teve como objetivo avaliar a recuperação da locomoção e a cicatrização óssea de fraturas do ílio fixadas por parafusos e fios de aço cimentados com PMMA em cães.

\section{MATERIAL E MÉTODOS}

Foram operados 16 cães com fratura no ílio (Figura 1-A), sendo que cinco deles tinham fratura bilateral. O protocolo anestésico constituiu de medicação pré-anestésica e indução com cloridrato de acetilpromazina ou diazepam, e propofol, respectivamente; infiltração epidural com cloridrato de bupivacaína e manutenção da anestesia com halotano.
A fratura foi acessada por meio de abordagem lateral, de acordo com a descrição de PIERMATTEI \& JOHNSON (2004). Os fragmentos ósseos foram reposicionados com instrumentos ortopédicos. $\mathrm{Na}$ seqüência, perfurou-se o osso para inserção dos parafusos. Em cada segmento da fratura, dois a três parafusos foram implantados em série no sentido longitudinal ou transverso do osso, com distância entre eles de pelo menos duas vezes o diâmetro do parafuso. Nas fraturas localizadas na divisa entre o ílio e a região do acetabulo, os parafusos foram inseridos longitudinalmente na face dorsal do acetábulo.

Todos os parafusos inseridos ficaram 5 a $10 \mathrm{~mm}$ saliente na cortical de inserção. Para auxiliar a fixação transcirúrgica foi colocada uma banda de tensão com fio de aço ortopédico nos parafusos adjacentes à linha de fratura (Figura 1- B e C).

O cimento ósseo ${ }^{a}$ foi preparado seguindo as recomendações do fabricante. Adicionalmente, misturou-se $1 \mathrm{~g}$ de cefazolina sódica liofilizada para cada $20 \mathrm{~g}$ de polímero. Essa mistura foi aspirada por seringa plástica esterilizada e aplicada entre e sobre os parafusos (Figura 1-D). Quando desencadeou a reação exotérmica, foi irrigada com solução fisiológica para auxiliar a dissipação do calor. Após o endurecimento, o local cirúrgico foi novamente lavado e a síntese dos planos musculares, subcutâneos e pele foi realizada com suturas utilizadas rotineiramente na clínica cirúrgica e fio de mononáilon.

O acompanhamento pós-operatório foi realizado mediante exames clínicos nos dias sete, 30 , 60 e 90. A locomoção dos animais foi classificada em insatisfatória: animal não apóia o membro para caminhar, satisfatória: claudicação residual enquanto caminha, e adequada: quando o animal caminha normalmente. Foi realizado exame radiográfico pós-cirúrgico para avaliar a redução da fratura e o alinhamento ósseo. Nos dias 30, 60 e 90, foram realizados exames radiográficos para avaliar a evolução da reparação óssea.

\section{RESULTADOS E DISCUSSÃO}

Dos cinco cães com fratura bilateral do ílio, dois foram submetidos à osteossíntese bilateral, realizada seqüencialmente no mesmo procedimento. Os outros três cães manifestaram instabilidade hemodinâmica transcirúrgica e optou-se por estabilizar somente um lado.

A abordagem cirúrgica lateral ao ílio proporcionou adequada exposição óssea nas fraturas localizadas cranialmente à inserção do músculo reto femoral. Duas fraturas apresentaram-se caudal a esse ponto, acerca do limite com o acetábulo. Nessas osteossínteses, a manipulação do segmento caudal da

Ciência Rural, v.38, n.6, set, 2008. 

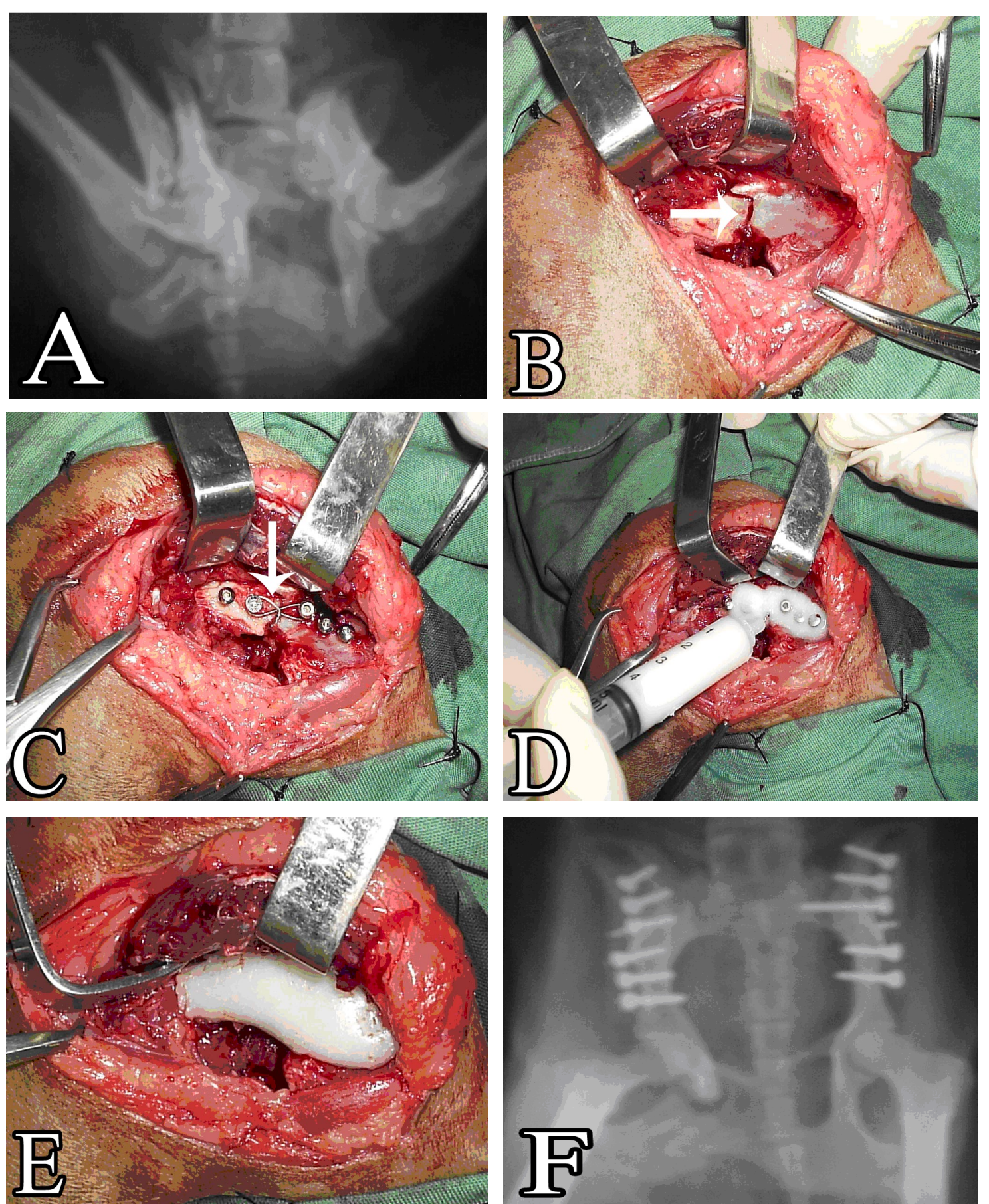

Figura 1 - A - Imagem radiográfica da pelve de cão apresentando fraturas múltiplas, incluindo ílio bilateral. B - Fratura transversa de ílio de cão exposta cirurgicamente (seta). C - Parafusos inseridos no ílio e fio de aço coadjuvando a redução (seta). D - Aplicação do PMMA entre e sobre os implantes metálicos. E - PMMA moldado e polimerizado sobre os implantes. F - Imagem radiográfica obtida após estabilização cirúrgica das fraturas em ílio observadas na figura A.

fratura ficava prejudicada devido a inserções dos músculos glúteos ao trocanter maior, que impossibilitam expô-lo satisfatoriamente. A abordagem foi então ampliada caudalmente com a osteotomia do trocanter maior e obteve-se o espaço adequado para proceder a osteossíntese.

Todos os cães foram operados entre o terceiro e o nono dia após o traumatismo (Tabela 1). Nove 
Tabela 1 - Identificação dos cães e informações sobre o lado da fratura, tempo decorrido até a cirurgia, estreitamento pélvico residual e recuperação funcional. Recife, janeiro 2005

\begin{tabular}{|c|c|c|c|c|}
\hline N. e dados do animal & Lado fraturado & Tempo trauma-cirurgia & Estreitamento pélvico & Resultado funcional \\
\hline 1- F, 1 ano, $1,8 \mathrm{~kg}$, Pinscher & $\mathrm{E}$ & 7 dias & Discreto & Adequado \\
\hline 2- M, 4 anos, 6,5kg, Poodle & $\mathrm{E}$ & 9 dias & Não & Adequado \\
\hline 3- M, 2 anos, $16 \mathrm{~kg}$, SRD & $\mathrm{D}$ & 9 dias & Não & Adequado \\
\hline 4- F, 8 anos, 4,5kg, Pinscher & $\mathrm{D}$ & 8 dias & Não & Adequado \\
\hline 5- M, 10 meses, $4 \mathrm{~kg}$, Pinscher & $\mathrm{E}$ & 6 dias & Não & Adequado \\
\hline 6- F, 3 anos, 4kg, Poodle & $\mathrm{D}$ & 4 dias & Não & Adequado \\
\hline 7-M, 7 meses, 6,5kg, Poodle & $\mathrm{E}$ & 9 dias & Moderado & Satisfatório \\
\hline *8- M, 1 ano, 3,5kg, Poodle & $\mathrm{E}$ & 6 dias & Discreto & Adequado \\
\hline 9- F, 2 anos, 4,7kg, Poodle & $\mathrm{E}$ & 5 dias & Não & Adequado \\
\hline 10- M, 6 anos, 4kg, Poodle & $\mathrm{E}$ & 7 dias & Discreto & Adequado \\
\hline 11- M, 2 anos, 3,5kg Poodle & $\mathrm{D}$ & 7 dias & Não & Adequado \\
\hline 12- M, 1 ano, 3,5kg Poodle & $\mathrm{E}$ & 5 dias & Não & Adequado \\
\hline 13- F, 4 anos, 5kg, SRD & $\mathrm{D}$ & 3 dias & Não & Adequado \\
\hline 14- F, 4 anos, 5kg, SRD & $\mathrm{E}$ & 7 dias & Não & Adequado \\
\hline 14- F, 4 anos, 5kg, SRD & $\mathrm{D}$ & 7 dias & Não & Adequado \\
\hline *15- F, 8 meses, $12 \mathrm{~kg}, \mathrm{SRD}$ & $\mathrm{E}$ & 2 dias & Não & Adequado \\
\hline 15- F, 8 meses, $12 \mathrm{~kg}$, SRD & $\mathrm{D}$ & 2 dias & Discreto & Adequado \\
\hline 16- F, 11 anos, $12 \mathrm{~kg}, \mathrm{SRD}$ & $\mathrm{D}$ & 5 dias & Não & Adequado \\
\hline
\end{tabular}

Quebra do PMMA, F: fêmea, M: macho, SRD: sem raça definida, E: lado esquerdo, D: lado direito.

osteossínteses foram realizadas entre o sétimo e o nono dia. Os planos musculares da abordagem cirúrgica apresentavam considerável rigidez que dificultava a dissecação dos tecidos. Pôde-se constatar claramente que as lesões iatrogênicas causadas para abordar a fratura foram mais graves em comparação aos cães que foram operados mais precocemente. Em especial citase o músculo glúteo profundo que era quase que totalmente danificado durante a elevação subperiosteal, para expor o corpo do ílio. As extremidades da fratura tiveram que ser debridadas porque estavam envolvidas por tecido de reparação, que é produzido para formar um calo primário e estabilizar o osso.

O tecido de reparação provoca aderência entre os planos anatômicos da abordagem cirúrgica, diminuindo assim a elasticidade tecidual que dificulta a redução da fratura. É importante salientar que o calo primário também se estabelece nas fraturas do púbis e do ísquio que ocorrem juntamente com a fratura do ílio (PIERMATTEI \& FLO, 1999), restringindo a mobilidade do fragmento caudal do ílio - que é um segmento ósseo grande por ser contínuo com a articulação coxofemoral e uma parte do púbis e ísquio. Assim ele deverá primeiramente ser deslocado em sentido caudal para coaptar a fratura ilíaca e depois lateralmente para restaurar o diâmetro do canal pélvico. Esta última manobra realiza-se fixando ao trocanter maior uma pinça de redução de fragmentos para fazer tração lateral. Apesar disso, entre os cães operados no período em questão, três (no 1,7 e 10 ) permaneceram com estreitamento discreto a moderado do canal pélvico.
Analisando este resultado do ponto de vista funcional do membro pélvico, somente o cão no 7 permaneceu claudicante. Nesse caso, além do estreitamento pélvico, a redução da fratura oblíqua do corpo do ílio também não foi possível de ser atingida e o fragmento caudal foi fixado aproximadamente $1 \mathrm{~cm}$ cranialmente à posição anatômica e com leve inclinação ventral. Acredita-se que a claudicação persistente é conseqüente à posição incorreta da articulação coxofemoral no contexto tridimensional da pelve e mais a alteração no ângulo de contato entre a cabeça do fêmur e o acetábulo, que ocorre devido ao apoio do membro no solo. Essa incongruência articular pode ser a causa imediata da dor, bem como um possível fator desencadeante de doença articular degenerativa a médio e longo prazo.

No caso das nove osteossínteses realizadas entre o terceiro e sexto dia, a abordagem à fratura e redução óssea foram menos trabalhosas porque os tecidos moles eram facilmente dissecados e afastados. Dois cães permaneceram com estreitamento pélvico discreto, detectado ao exame radiográfico pósoperatório, ocasionado pela sobreposição de uma fratura no corpo do ísquio ispsilateral a fratura do ílio (Figura 1 - F), que impediu o alinhamento do segmento caudal do coxal. Para evitar esse inconveniente, acredita-se que a tração caudal da asa do ísquio concomitante à tração lateral do trocanter maior permitirá alinhar corretamente o coxal. BRESHEARS et al. (2004) relataram a ocorrência de 18 casos de

Ciência Rural, v.38, n.6, set, 2008. 
estreitamento do canal pélvico em 45 osteossínteses de ílio realizadas com placa e parafuso, porém, esses autores não especificaram as causas do estreitamento.

A implantação dos parafusos foi o passo seguinte à redução da fratura. A perfuração do osso e o preparo dos orifícios de inserção foram as mesmas descritas por PIERMATTEI \& FLO (1999). A posição dos parafusos no osso pode variar de acordo com a apresentação da fratura. Essa flexibilidade é possível porque a posição dos parafusos não está prédeterminada, como na fixação destes juntamente com placas metálicas. Portanto, o cirurgião pode escolher local com boa estrutura óssea para fixar os implantes. Esta facilidade trás conforto durante a execução da técnica, principalmente em fraturas de ílio com apresentações incomuns. Sempre que possível, é preferível implantar os parafusos no sentido longitudinal do osso, da forma mais homogênea possível, para que as forças geradas durante a locomoção sejam mais bem distribuídas. Na área da articulação sacro-ilíaca, quando a apresentação da fratura possibilitava, implantou-se um parafuso cortical mais longo (Figura 1-F) ou mesmo um de osso esponjoso, para dar um ponto firme de ancoragem ao cimento ósseo, principalmente em cães de porte muito pequeno (cães $n^{0}$ 1, 8, 11 e 12 - Tabela 1 ), que possuem delgada estrutura óssea na asa do ílio.

A implantação dos parafusos perpendicularmente ao eixo longo do osso pode ser empregada em cães de porte pequeno com fratura na asa ou caudais no corpo do ílio, acerca dos limites com o acetábulo, porém, deve-se evitar implantá-los muito perto das margens do osso e predispondo-os á avulsão, já que nessa região o ílio tem a menor largura e recebe considerável carga estática e dinâmica provinda da locomoção (OLMSTEAD, 1995). Como alternativa, a ampliação caudal da abordagem por meio da ostectomia do trocanter maior expõe porções mais caudais do coxal e os parafusos poderão ser fixados na superfície crâniodorsal do acetábulo.

Os fios de aço colocados entre os parafusos em forma de banda de tensão auxiliaram na redução e manutenção somente nas fraturas com bordas perpendiculares à superfície do osso. À medida que o fio é torcido, gera compressão interfragmentária e o encaixe das extremidades estabiliza a fratura, facilitando a posterior aplicação e a moldagem do cimento ósseo. Quando a fratura tem bordas chanfradas, seja por perda óssea de uma das corticais ou pela simples apresentação da fratura, o aperto do fio de aço provoca deslizamento entre as partes do osso, prejudicando o alinhamento. Para aplicar o cimento ósseo e até seu endurecimento, é preciso manter a redução da fratura com pinças ortopédicas fixada ao trocanter maior (Figura 1-C).
A cefazolina sódica misturada ao cimento ósseo foi uma medida profilática adotada com o objetivo de prevenir a infecção óssea. Autores como MALCHAU et al. (1993) e BOURNE (2004) relatam que o uso de cimento ósseo impregnado com antibiótico diminui as infecções profundas em artroplastia coxofemoral e do joelho e exercem efeito bactericida durante pelo menos sete a 10 dias. No presente trabalho, não foi possível avaliar esse dado, apesar de não ter sido constatada infecção óssea ou mesmo de planos anatômicos mais superficiais.

Previamente à reação exotérmica, a consistência viscoelástica permite modelagem do cimento ósseo e acomodamento sobre os implantes metálicos e à superfície do osso. Desta forma, a técnica pode ser aplicada sobre ossos de tamanhos distintos e em diferentes partes do mesmo osso. A espessura do PMMA também pode ser ajustada no transcirúrgico de acordo com a necessidade, baseada no peso do animal. No momento não se encontrou dado de literatura que determinasse a espessura ideal do implante de PMMA. Nos animais operados, ela foi determinada pela parte do parafuso exposta na superfície do osso, que variou aproximadamente entre $5 \mathrm{~mm}$ nos animais menores (a exemplo dos animais $\mathrm{n}^{\circ} \mathbf{1}$, 11, e 12 - tabela 1) e 10mm para os animais maiores (animais nํㅜ 3, 15 e 16 - tabela 1). Não foram observadas falhas da estabilização quando a espessura do PMMA era uniforme.

A quantidade de PMMA utilizada para cada caso variou de acordo com o comprimento do osso que foi estabilizado e também com a espessura, ambos variando com o tamanho do animal. O volume utilizado não foi medido. Porém, em nenhum dos casos chegouse a utilizar a metade da mistura, que compreende $20 \mathrm{~g}$ de polímero (pó) e 20ml de monômero (líquido).

Após o termino da reação exotérmica que polimeriza o cimento ósseo, este se torna um bloco rígido que envolve e fixa completamente os parafusos, além de estar em íntimo contato com a superfície do osso, favorecendo a estabilização da fratura, proporcionando fixação do osso e conseqüentemente conforto para a locomoção. A possibilidade de quebra, afrouxamento ou migração individual dos parafusos é improvável, uma vez que eles literalmente encontramse cimentados. BRESHERS et al. (2004) citam que o afrouxamento de parafusos é a complicação mais comum relacionada à falha de implantes metálicos em estabilizações de fraturas ilíacas, problema observado em $21 \%$ dos casos do estudo retrospectivo realizado.

Ao exame radiográfico pós-operatório imediato, o cão $\mathrm{n}^{\circ} 8$ apresentou imagem radioluscente no interior do PMMA, sugerindo uma falha de preenchimento. No exame radiográfico aos 30 dias de 
pós-operatório, o cimento ósseo apresentava-se descontínuo no local da radioluscência. A partir disso, concluiu-se que a falha de preenchimento provocou um ponto de fragilidade e possibilitou a quebra do implante. Mesmo não havendo mais fixação da fratura pelo PMMA, o deslocamento ósseo foi mínimo, levando a crer que já havia estabelecido um calo ósseo primário quando ocorreu a quebra. Optou-se por não reintervir e, nas avaliações radiográficas subseqüentes, a posição dos fragmentos continuou igual.

Até a intercorrência descrita acima, o PMMA era aplicado quando em estado plástico, semelhante a uma goma, o que pode ter predisposto a falta de uniformidade. Nos procedimentos seguintes (12 osteossínteses), o cimento foi aspirado com seringa plástica quando estava em estado líquido e aplicado sobre os implantes quando em estado pastoso, facilitando a dispersão e acomodamento do mesmo entre os implantes.

No cão $\mathrm{n}^{\mathrm{0}} 15$ ocorreu quebra do cimento ósseo, observada no segundo dia após a cirurgia. A causa atribuiu-se a uma esquírola má alinhada da fratura que era cominutiva e fez com que o cimento ósseo ficasse fino nesse ponto, tornando-o frágil para suportar as forças após a fixação. Esta falha não foi detectada durante a osteossíntese e possivelmente tenha ocorrido por alguma mobilidade da fratura enquanto o PMMA ainda estava mole. Esse paciente foi submetido a novo procedimento para o osso. Os implantes colocados no procedimento anterior foram mantidos devido à dificuldade de remoção do PMMA. Sobre este foi implantada uma placa com parafusos metálicos. A recuperação ocorreu normalmente. A fratura cominutiva obviamente dificulta consideravelmente a manutenção dos fragmentos do osso em redução, uma vez que a tendência é o colapso e o desalinhamento devido à tensão dos músculos, a qual gera uma força que é de oposição. Nessa circunstância deve-se pinçar o trocanter maior com uma pinça de redução de fragmentos e, com tração no sentido caudal, manter a fratura imóvel até o endurecimento do cimento ósseo. Nas esquírolas que suportam implantes, pode-se inserir parafusos para mantê-las alinhadas após o endurecimento do cimento ósseo.

Dos 16 animais operados, 12 apresentaram parcial sustentação do peso no sétimo dia de pósoperatório. Após o trigésimo dia, 15 animais utilizaram normalmente o membro durante a deambulação, e discreta manifestaram claudicação intermitente ao correr. Ao final do período de avaliação, a locomoção apresentava-se normal. A significativa melhora observada na primeira avaliação, bem como a satisfatória utilização do membro aos 30 dias, certamente ocorreu pelo alinhamento satisfatório e pela rígida fixação da fratura ilíaca. O cão nº 7 (tabela 1), por razões já discutidas anteriormente, ao final do período de avaliação, continuava com discreta claudicação, que não era limitante para as atividades físicas que realizava diariamente em seu ambiente.

Nos exames radiográficos realizados aos 30 dias de pós-operatório, pode-se observar reação periosteal na cortical medial do ílio concentrada sobre a linha de fratura, em todas as osteossínteses. Nas avaliações seguintes, observou-se progressivo aumento da radiopacidade na linha de fratura e na citada reação periosteal, sendo que entre 60 e 90 dias a fratura apresentava-se completamente envolvida por calo ósseo. Esta evolução favorável da reparação óssea provavelmente ocorreu pelos seguintes motivos: rígida estabilização, precoce retorno às funções de sustentação próprias do osso e a vasta musculatura glútea adjacente à fratura, proporcionando adequado suprimento sanguíneo.

\section{CONCLUSÃO}

Conclui-se que, em cães com peso de até $16 \mathrm{~kg}$, a fixação de fraturas no ílio com parafusos e fios de aço cimentados com PMMA proporciona adequada estabilidade ao osso, precoce recuperação funcional e reparação da fratura.

\section{AGRADECIMENTOS}

Ao Conselho Nacional de Desenvolvimento Científico e Tecnológico (CNPq) e à Coordenação de Aperfeiçoamento de Pessoal de Nível Superior (CAPES), pelas bolsas de PIBIC e mestrado concedidas.

\section{FONTE DE AQUISIÇÃO}

${ }^{\text {aCimpox }}{ }^{\circledR}$ - Ônix ortopedia ind. e com. LTDA - Ilha de Itamaracá - PE

\section{REFERÊNCIAS}

ALVAREZ, A.O.; MARTINEZ, E.M. Use of polymethylmethacrilate as a cement for ilium fixation in triple pelvic osteotomy. In: CONGRESO DE LAASOCIACION MUNDIAL DE MEDICINA VETERINARIA DE PEQUEÑOS ANIMALES, 23., 1998, Buenos Aires, Argentina. Anais... Buenos Aires: WSAVA, 1998. V.1, p.540.

BETTS, C.W. Fraturas pélvicas. In: SLATTER, D. Manual de cirurgia de pequenos animais. 3.ed. São Paulo: Manole, 1998. V.2, cap.134, p.2094-2113.

BOURNE, R.B. Prophylactic use of antibiotic bone cement. Journal of Arthroplasty, v.19, n.4, p.69-71, 2004.

Ciência Rural, v.38, n.6, set, 2008. 
BRESHEARS, L. A. et al. The radiographic evolution of repaired canine ilial fractures (69 cases). Veterinary and Comparative Orthopaedics and Traumatology, v.17, n.2, p.64-72, 2004.

BROWN, S.G. et al. Plate fixation of ilial shaft fractures in the dog. Journal of American Veterinary Medical Association, v.167, n.6, p.472-478, 1975.

JACOBSON, A.; SCHRADER, S.C. Peripheral nerve injury associated with fracture of fracture-dislocation of the pelvis in dogs and cats: 34 cases (1978-1982). Journal of American Veterinary Medical Association, v.190, n.5, p.569-572, 1987.

LEWIS, D.D. et al. Results o screw/wire/polymethylmethacrylate composite fixation for acetabular fracture repair in 14 dogs. Veterinary Surgery, v.26, n.3, p.223-224, 1997.

LIDBETTER, D.A.; WONG, W.T. Surgical treatment of vertebral subluxation using screws and polymethylmethacrylate in a dog. Australian Veterinary Practice, v.30, n.2, p.84$88,2000$.

MALCHAU, H. et al. Prognosis of total hip replacement in Sweden. Follow-up of 92.675 operations performed 1978-1990. Acta Orthopaedica Scandinava, v.64, n.5, p.497-506, 1993.
OLMSTEAD, M.L. Fractures of the bone of the hind limbs. In: OLMSTEAD, M.L. Small animal orthopedics. Louis: Mosby, 1995. Cap.9, p.219.

PIERMATTEI, D.L.; FLO, G.L. Manual de ortopedia e tratamento das fraturas dos pequenos animais. 3.ed. São Paulo: Manole, 1999. 694p.

PIERMATTEI, D.L.; JOHNSON, K.A. Surgical approaches to the bones and joints of the dog and cat. 4.ed. Philadelphia: Saunders, 2004. 416p.

ROUSE, G.P.; MILLER, J.I. The use of methylmethacrylate for spinal stabilization. Journal of American Animal Hospital Association, v.11, n. 3, p.418-425, 1975

SUMMER-SMITH, G.; WATERS, E.H. The adjunctive use of methacrylate bone cement in the stabilization of multiple fractures. Journal of American Animal Hospital Association, v.12, n.6, p.778-781, 1976.

WENDELBURG, K.L. Disorders of the hip joint in the canine athlete. In: BLOOMBERG, M.S. Canine sports medicine and surgery. Philadelphia: Saunders, 1998. Cap.22, p.174195.

WONG, W.T.; EMMS, S.G. Use of pins and methylmethacrylate in stabilization of spinal fractures and luxations. Journal of Small Animal Practice, v.33, n.9, p.415-422, 1992 